CLINICAL STUDY

\title{
Changes in the prevalence of hypothyroidism: the HUNT Study in Norway
}

\author{
Bjørn Olav Åsvold ${ }^{1,2}$, Lars J Vatten ${ }^{1,3}$ and Trine Bjøro ${ }^{4,5}$ \\ ${ }^{1}$ Department of Public Health, Faculty of Medicine, Norwegian University of Science and Technology, Postboks 8905, N-7491 Trondheim, Norway, \\ ${ }^{2}$ Department of Endocrinology, St Olavs Hospital, Trondheim University Hospital, N-7006 Trondheim, Norway, ${ }^{3}$ Department of Epidemiology, \\ Harvard School of Public Health, Boston, Massachusetts 02115, USA, ${ }^{4}$ Division of Diagnostics and Intervention, Department of Medical Biochemistry, \\ Oslo University Hospital, N-0310 Oslo, Norway and ${ }^{5}$ Faculty of Medicine, University of Oslo, N-0316 Oslo, Norway \\ (Correspondence should be addressed to B O Åsvold at Department of Public Health, Faculty of Medicine, Norwegian University of Science and Technology; \\ Email: bjorn.o.asvold@ntnu.no)
}

\begin{abstract}
Objective: Untreated hypothyroidism is common in iodine-replete areas. Frequent thyroid function testing and use of levothyroxine treatment for subclinical hypothyroidism suggest that the prevalence may have decreased. Therefore, in this study, we examined changes in the prevalence of hypothyroidism in a Norwegian county from 1995-1997 to 2006-2008.

Design: Population surveys of 33917 individuals in 1995-1997 and 49180 individuals in 2006-2008 were carried out.

Methods: We compared the prevalence of untreated overt, untreated subclinical, and treated hypothyroidism between 1995-1997 and 2006-2008.

Results: The prevalence of untreated overt hypothyroidism among women decreased by $84 \%$ from 1995-1997 (0.75\%) to 2006-2008 (0.12\%) (prevalence ratio (PR) 0.16; 95\% CI 0.10-0.26). The corresponding decrease among men was $43 \%$ from 0.21 to $0.12 \%$ (PR $0.57 ; 95 \%$ CI $0.28-1.16$ ). The prevalence of untreated subclinical hypothyroidism decreased by $64 \%$ from 3.0 to $1.1 \%$ in women (PR 0.36; 95\% CI 0.31-0.42) and decreased by 54\% from 2.1 to $1.0 \%$ in men (PR $0.46 ; 95 \%$ CI 0.38-0.56). Conversely, the prevalence of treated hypothyroidism among women increased by $60 \%$ from 5.0 to $8.0 \%$ (PR 1.60, 95\% CI 1.50-1.71), and the corresponding prevalence in men doubled from 1.0 to $2.0 \%$ (PR 1.96; 95\% CI 1.59-2.41). The prevalence of any form of hypothyroidism remained essentially similar at $9 \%$ in women and $3 \%$ in men.

Conclusions: The prevalence of untreated hypothyroidism in this Norwegian county decreased strongly from 1995-1997 to 2006-2008. The findings suggest that the prevalence of untreated hypothyroidism in populations with easy access to thyroid function testing and levothyroxine treatment may now be low.
\end{abstract}

European Journal of Endocrinology $169613-620$

\section{Introduction}

From large population studies carried out in the 1970s to 1990 s, we have learnt that untreated hypothyroidism is common in iodine-replete areas. In these studies, $\sim 0.2-$ $0.5 \%$ of the participants had biochemically overt hypothyroidism and 4-10\% had subclinical hypothyroidism $(1,2,3,4,5,6)$. Subsequent observational evidence has suggested that subclinical hypothyroidism may be associated with an increased risk of coronary heart disease, adverse pregnancy outcomes, and progression to clinical hypothyroidism $(1,7)$. The knowledge of the high prevalence and potential hazards of hypothyroidism, as well as increased availability of thyroid function tests, may have led to more frequent thyroid function testing and liberal treatment of subclinical hypothyroidism. However, it is not known to which extent the prevalence of untreated hypothyroidism may have changed. In this population-based study, we, therefore, examined changes in the prevalence of hypothyroidism in a Norwegian county during an 11-year period ranging from 19951997 to $2006-2008$.

\section{Subjects and methods}

\section{Study population}

The HUNT Study is a series of three surveys carried out in the Nord-Trøndelag county in Norway $(8,9)$. In each of the surveys, all the residents who were aged 20 years or above were invited to participate, and the study included comprehensive questionnaires, clinical examination, and blood sampling. The second (HUNT 2) and third (HUNT 3) surveys included thyroid function measurements. 
In HUNT 2 (1995-1997), 93898 people were invited, and 65215 (69\%) participated (8, 9). Serum thyrotropin (TSH) concentrations were measured in subsamples of the population, including all women aged 40 years or above, a $50 \%$ random sample of men aged 40 years or above, and 5\% random samples of women and men aged below 40 years. In total, TSH concentrations were measured in 33948 participants from these samples. Among these participants, we excluded 31 who did not reply to the questionnaire items on thyroid diseases (2), leaving 33917 participants (23 274 women and 10643 men) for analysis.

In HUNT 3 (2006-2008), 93860 people were invited, and 50807 (54\%) participated (9). Serum TSH measurement was planned for all the subjects, and TSH concentrations were measured in 49180 participants (26822 women and 22358 men) who were included in the present analysis.

\section{Thyroid function in HUNT 2}

If TSH concentrations were above $4.0 \mathrm{mU} / \mathrm{l}$, serum free thyroxine and TPO antibody concentrations were measured. The measurements were carried out at the Hormone Laboratory, Aker University Hospital (Oslo, Norway), using DELFIA hTSH Ultra (total analytical variation $<5 \%$ ) and DELFIA FT4 (total analytical variation $<7 \%$ ) from Wallac Oy (Turku, Finland) and a luminoimmunoassay for TPO antibodies from B.R.A.H.M.S. Diagnostica GmbH (Berlin, Germany). The reference ranges were $8-20 \mathrm{pmol} / \mathrm{l}$ for free thyroxine and $<200 \mathrm{U} / \mathrm{ml}$ for TPO antibodies. For TSH, the laboratory's reference range was $0.2-$ $4.5 \mathrm{mU} / \mathrm{l}$, but subsequent analyses indicated that $0.5-$ $3.5 \mathrm{mU} / \mathrm{l}$ may be a more appropriate reference range for this population (2). In this study, we used a TSH concentration of $4.5 \mathrm{mU} / \mathrm{l}$ as a cut-off to indicate hypothyroidism, as has been done in the recent studies carried out by the Thyroid Studies Collaboration $(7,10)$.

The questionnaire included items on current or previous thyroid diseases, including the use of levothyroxine or thionamides. The prevalence of hypothyroidism in HUNT 2 has been reported previously (2), but we re-estimated the prevalence in the present study, using similar definitions of hypothyroidism for HUNT 2 and HUNT 3.

\section{Thyroid function in HUNT 3}

If TSH concentrations were above $3.0 \mathrm{mU} / \mathrm{l}$, serum free thyroxine and TPO antibody concentrations were measured. TSH (total analytical variation $<5 \%$ and reference range $0.20-4.5 \mathrm{mU} / \mathrm{l}$ ), free thyroxine (total analytical variation $<5 \%$ and reference range $9.0-$ $19.0 \mathrm{pmol} / \mathrm{l}$ ), and TPO antibody (reference range $\leq 5.6 \mathrm{U} / \mathrm{ml}$ ) concentrations were measured at Levanger Hospital, Nord-Trøndelag Hospital Trust, using chemiluminescent microparticle immunoassays on an
Architect ci8200 obtained from Abbott, with reagents obtained from Architect iSystem (Abbott Ireland, Longford, Ireland; and Abbott Laboratories). The methods used for TSH measurement in HUNT 2 and HUNT 3 were compared using blood samples obtained from 94 individuals. For TSH concentrations below $5 \mathrm{mU} / \mathrm{l}$, the results did not systematically differ between the methods. For TSH concentrations above $5 \mathrm{mU} / \mathrm{l}$, the values were, on average, 3.7\% lower when using the Architect method (HUNT 3) than when using the DELFIA method (HUNT 2).

We used the unique 11-digit identity number of every Norwegian citizen to link the data to the Norwegian Prescription Database (www.norpd.no), which includes information on virtually all prescriptions dispensed to non-institutionalized inhabitants in Norway since January 2004. From this database, we obtained individual information on dates on which levothyroxine and thionamides had been dispensed.

\section{Classification of hypothyroidism}

In each survey, we classified hypothyroid participants as having treated, untreated overt, or untreated subclinical hypothyroidism. Treated hypothyroidism was defined as the use of levothyroxine without the use of thionamides, as indicated by self-report (for HUNT 2) or information from the prescription database (for HUNT 3 ). For HUNT 3, short-term levothyroxine use a long time before the examination (indicated by no dispensing during the last 6 months and less than three dispensings in total) did not qualify as treated hypothyroidism. For people who did not use levothyroxine or thionamides, we defined untreated overt hypothyroidism as having TSH concentrations above $4.5 \mathrm{mU} / \mathrm{l}$ combined with free thyroxine concentrations below the laboratory's reference range and untreated subclinical hypothyroidism as having TSH concentrations above $4.5 \mathrm{mU} / \mathrm{l}$ combined with free thyroxine concentrations at the lower reference limit or higher.

\section{Statistical analyses}

For each type of hypothyroidism, we estimated the prevalence in HUNT 2 and HUNT 3 and the prevalence ratio (PR, with 95\% CI) between the surveys using a logbinomial regression model. We analyzed women and men separately and adjusted for age $(<40,40-49$, $50-59,60-69,70-79$, or $\geq 80$ years). We also estimated the prevalence of hypothyroidism in each survey by age group. Furthermore, we studied the change in the prevalence of subtypes of untreated subclinical hypothyroidism defined by TSH concentration $(4.6-6.9,7.0-9.9$, or $10.0 \mathrm{mU} / \mathrm{l}$ or higher) or TPO antibody status (positive or negative antibody status, using the upper reference limit as the cut-off level). In additional analyses, we examined whether the PRs changed after adjustment for BMI, smoking habits, 
and alcohol consumption. In the regression model, we used a clustered sandwich estimator of variance to account for repeated measurements among those who participated in both surveys. In HUNT 2, participants aged below 40 years were weighted due to differences in sampling probability.

To examine the treatment practices of subclinical hypothyroidism in this population, we estimated the prevalence of each type of hypothyroidism in HUNT 3 among the participants with untreated subclinical hypothyroidism in HUNT 2 who had also participated in HUNT 3.

For those who participated in both surveys, the detection of hypothyroidism in HUNT 2 could have influenced the prevalence observed in HUNT 3. To evaluate this possibility, we compared the prevalence of hypothyroidism in HUNT 3 between participants who had their thyroid function tested in HUNT 2 and those who had not. This analysis was carried out in participants aged 50 years or above in HUNT 3, corresponding to the 40-year age cut-off for thyroid function measurement in HUNT 2.

To evaluate whether the prevalence of treated hypothyroidism differed between the study participants and the general population, we compared the prevalence of levothyroxine use in 2005 (the year prior to HUNT 3 examinations) between the participants of HUNT 3, the total population of Nord-Trøndelag, and the total Norwegian population, using population-level data on the prescriptions of levothyroxine from the Norwegian Prescription Database. We estimated this prevalence by sex and age group (10-year categories).

In the results reported herein, we used the laboratory's lower reference limit for free thyroxine to differentiate between overt and subclinical hypothyroidism, but this limit was slightly higher in HUNT 3 $(9.0 \mathrm{pmol} / \mathrm{l})$ than in HUNT $2(8.0 \mathrm{pmol} / \mathrm{l})$. Therefore, we repeated the analyses using $8.0 \mathrm{pmol} / \mathrm{l}$ as the reference limit in both the surveys, but the use of this alternative reference limit did not substantially influence the results. All the statistical analyses were carried out using Stata version 12.1 for Windows (Stata Corporation, College Station, TX, USA).
The study was approved by the Regional Committee for Medical Research Ethics and by the Norwegian Data Inspectorate, and all the participants gave their informed consent.

\section{Results}

The characteristics of the participants are given in Table 1 . The proportion of participants by age group is given in Table 2. A total of 13085 women and 5708 men had their thyroid function tested in both the surveys: 10189 women and 4935 men in 1995-1997 (HUNT 2) only, and 13737 women and 16650 men in 2006-2008 (HUNT 3) only.

The prevalence of untreated overt hypothyroidism among women decreased by $84 \%$ from 1995-1997 $(0.75 \%)$ to $2006-2008(0.12 \%)$ (PR 0.16 ; 95\% CI $0.10-0.26)$. The corresponding decrease among men was $43 \%$ from 0.21 to $0.12 \%$ (PR 0.57 ; $95 \%$ CI $0.28-$ 1.16). The prevalence of untreated subclinical hypothyroidism decreased by $64 \%$ from 3.0 to $1.1 \%$ in women (PR 0.36; 95\% CI 0.31-0.42) and by 54\% from 2.1 to $1.0 \%$ in men (PR 0.46; 95\% CI 0.38-0.56). Conversely, the prevalence of treated hypothyroidism in women increased by $60 \%$ from 5.0 to $8.0 \%$ (PR 1.60; 95\% CI 1.50-1.71), and the corresponding prevalence in men doubled from 1.0 to $2.0 \%$ (PR 1.96; 95\% CI 1.59-2.41). The prevalence of any of these forms of hypothyroidism remained essentially similar at $9 \%$ in women and 3\% in men (Table 3).

Changes in the prevalence of untreated and treated hypothyroidism were present across all the age groups, but the absolute changes were largest among women aged 60 years and above. For these women, the prevalence of untreated subclinical hypothyroidism decreased from $\sim 4$ to $1 \%$ between the surveys, whereas the prevalence of treated hypothyroidism increased from $\sim 8$ to $13 \%$ (Fig. 1 ).

The prevalence of untreated subclinical hypothyroidism decreased regardless of the concentrations of TSH or the presence of TPO antibodies, but the strongest decrease was observed for subclinical hypothyroidism with TSH concentrations of 7.0-9.9 mU/l (prevalence

Table 1 Characteristics of the study population.

\begin{tabular}{|c|c|c|c|c|}
\hline & \multicolumn{2}{|c|}{ Women } & \multicolumn{2}{|c|}{ Men } \\
\hline & 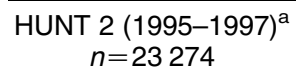 & $\begin{array}{c}\text { HUNT } 3 \text { (2006-2008) } \\
n=26822\end{array}$ & 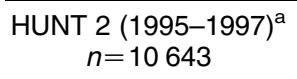 & $\begin{array}{c}\text { HUNT } 3(2006-2008) \\
n=22358\end{array}$ \\
\hline Age (years), median (IQR) & $49(36-64)$ & $53(40-64)$ & $49(37-64)$ & $54(42-64)$ \\
\hline Serum TSH $(\mathrm{mU} / \mathrm{l}){ }^{\mathrm{b}}{ }^{2}$ median (IQR) & $1.5(1.1-2.2)$ & $1.4(1.0-1.9)$ & $1.5(1.1-2.1)$ & $1.5(1.1-2.0)$ \\
\hline BMI $\left(\mathrm{kg} / \mathrm{m}^{2}\right)$, mean (S.D.) & $26.3(4.5)$ & $26.9(4.8)$ & $26.5(3.5)$ & $27.5(3.8)$ \\
\hline Current daily smokers (\%) & 28.9 & 21.3 & 29.0 & 17.8 \\
\hline
\end{tabular}

IQR, interquartile range.

aParticipants aged below 40 years were weighted due to differences in sampling probability.

${ }^{b}$ In people not using levothyroxine or thionamides. 
Table 2 Proportion (\%) of participants by age group in HUNT 2 (1995-1997) and HUNT 3 (2006-2008), by sex.

\begin{tabular}{lccccc}
\hline & \multicolumn{2}{c}{ Women } & & \multicolumn{2}{c}{ Men } \\
\cline { 2 - 3 } \cline { 5 - 6 } $\begin{array}{l}\text { Age group } \\
\text { (years) }\end{array}$ & $\begin{array}{c}\text { HUNT 2 } \\
(1995-\end{array}$ & $\begin{array}{c}\text { HUNT 3 } \\
(2006-\end{array}$ & & $\begin{array}{c}\text { HUNT 2 } \\
(1995-\end{array}$ & $\begin{array}{c}\text { HUNT 3 } \\
(2006-\end{array}$ \\
\hline $20-39$ & $1997)^{\mathrm{a}}$ & $2008)$ & & $1997)^{\mathrm{a}}$ & $2008)$ \\
\hline $40-49$ & 31.3 & 23.7 & & 29.8 & 20.3 \\
$50-59$ & 20.8 & 19.7 & & 21.3 & 19.8 \\
$60-69$ & 16.7 & 21.7 & & 18.1 & 23.6 \\
$70-79$ & 13.6 & 18.6 & & 14.8 & 20.4 \\
$\geq 80$ & 12.7 & 11.2 & & 12.2 & 11.7 \\
& 5.0 & 5.1 & & 3.8 & 4.3 \\
\hline
\end{tabular}

${ }^{\text {a }}$ Participants aged below 40 years were weighted due to differences in sampling probability.

in 2006-2008: $0.1-0.2 \%$ ) or TSH concentrations of $10.0 \mathrm{mU} / \mathrm{l}$ or above (prevalence in 2006-2008: 0.06\%) (Table 4). Among women, the prevalence of mildly elevated TSH concentrations $(4.6-6.9 \mathrm{mU} / \mathrm{l})$ without TPO antibodies decreased by $60 \%$ (PR 0.40; 95\% CI $0.30-0.52$ ) from 0.90 to $0.36 \%$. The corresponding decrease among men was 56\% (PR 0.44; 95\% CI $0.34-0.58$ ) from 1.07 to $0.47 \%$.

In additional analyses, we adjusted for BMI, smoking habits, and alcohol consumption to examine whether changes in these variables could explain the changes in the prevalence of hypothyroidism, but the PRs remained essentially unchanged after such an adjustment (data not shown).

To examine the treatment practices of subclinical hypothyroidism in this population, we studied the prevalence of treated and untreated hypothyroidism in HUNT 3 in 403 women and 114 men with untreated subclinical hypothyroidism in HUNT 2 who had also participated in HUNT 3. Among these participants, 66\% of women and $44 \%$ of men were treated for hypothyroidism in HUNT 3, and such treatment was particularly common among those with a strong TSH concentration elevation or TPO antibodies in HUNT 2 (Table 5).
To evaluate whether the detection of hypothyroidism in HUNT 2 could have influenced the prevalence in HUNT 3, we compared the prevalence of treated and untreated hypothyroidism in HUNT 3 between participants who had their thyroid function tested in HUNT 2 and those who had not, but the prevalence did not differ substantially between the groups (Table 6).

To evaluate whether the prevalence of treated hypothyroidism differed between the study participants and the general population, we compared the prevalence of levothyroxine use in 2005 between the participants of HUNT 3 and the total adult population of Nord-Trøndelag, but the prevalence was essentially similar in both the groups (Fig. 2). The prevalence of levothyroxine use in the NordTrøndelag county also did not differ substantially from that in the total Norwegian population, but among women aged 60 years and above, the prevalence of levothyroxine use was $\sim 1$ percentage point higher in the Nord-Trøndelag county than in the total Norwegian population (Fig. 2).

\section{Discussion}

In this population study, we examined changes in the prevalence of hypothyroidism within a Norwegian county during an 11-year period ranging from 19951997 to 2006-2008. The prevalence of untreated hypothyroidism decreased strongly, and in 2006-2008, the prevalence of untreated overt hypothyroidism was only $0.1 \%$ and that of untreated subclinical hypothyroidism was $1 \%$, with similar estimates for women and men. There was a corresponding increase in the prevalence of treated hypothyroidism, and thus, the prevalence of any form of hypothyroidism remained essentially similar at 9\% in women and 3\% in men.

The population-based design with repeated surveys enabled us to study long-term changes in the prevalence of hypothyroidism, and the large sample size allowed precise estimates. Linkage with the Norwegian

Table 3 Prevalence of hypothyroidism in HUNT 2 and HUNT 3 and ratios of the prevalence in HUNT 3 to that in HUNT 2, adjusted for age.

\begin{tabular}{|c|c|c|c|c|c|c|}
\hline \multirow[b]{2}{*}{ Type of hypothyroidism } & \multicolumn{2}{|c|}{ HUNT $2^{a}$ (1995-1997) } & \multicolumn{2}{|c|}{ HUNT $3^{\mathrm{b}}(2006-2008)$} & \multirow[b]{2}{*}{ Prevalence ratio } & \multirow[b]{2}{*}{$95 \% \mathrm{Cl}$} \\
\hline & Prevalence (\%) & $95 \% \mathrm{Cl}$ & Prevalence (\%) & $95 \% \mathrm{Cl}$ & & \\
\hline \multicolumn{7}{|l|}{ Women } \\
\hline Untreated overt & 0.75 & $0.51-1.00$ & 0.12 & $0.08-0.17$ & 0.16 & $0.10-0.26$ \\
\hline Untreated subclinical & 3.0 & $2.6-3.3$ & 1.1 & $0.9-1.2$ & 0.36 & $0.31-0.42$ \\
\hline Treated & 5.0 & $4.6-5.3$ & 8.0 & $7.7-8.3$ & 1.60 & $1.50-1.71$ \\
\hline Any & 8.7 & $8.2-9.3$ & 9.2 & $8.9-9.6$ & 1.06 & $1.00-1.12$ \\
\hline \multicolumn{7}{|l|}{ Men } \\
\hline Untreated overt & 0.21 & $0.08-0.34$ & 0.12 & $0.07-0.16$ & 0.57 & $0.28-1.16$ \\
\hline Untreated subclinical & 2.1 & $1.8-2.5$ & 1.0 & $0.9-1.1$ & 0.46 & $0.38-0.56$ \\
\hline Treated & 1.0 & $0.8-1.2$ & 2.0 & $1.8-2.2$ & 1.96 & $1.59-2.41$ \\
\hline Any & 3.4 & $3.0-3.8$ & 3.1 & $2.9-3.3$ & 0.92 & $0.81-1.05$ \\
\hline
\end{tabular}

a23 274 women and 10643 men.

b26 822 women and 22358 men. 

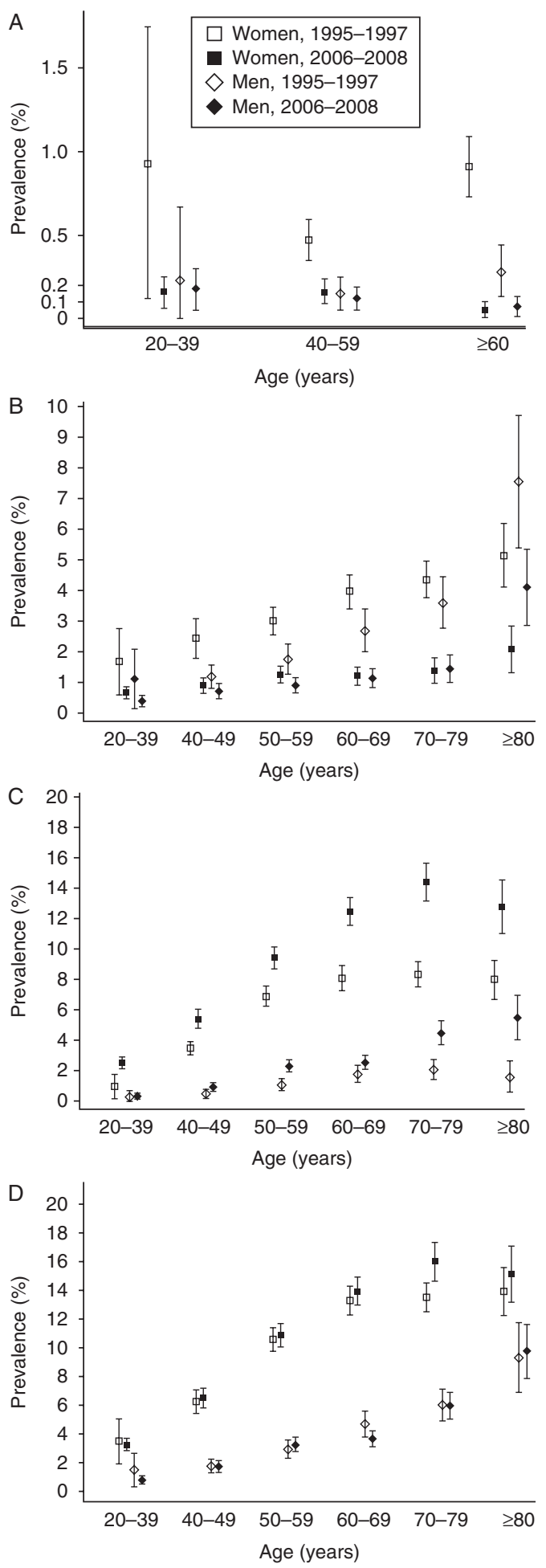

Figure 1 Prevalence $(\%$, with $95 \% \mathrm{Cl})$ of untreated overt hypothyroidism (A), untreated subclinical hypothyroidism (B), treated hypothyroidism (C), and any form of hypothyroidism (D) in 1995-1997 and 2006-2008, by sex and age group.
Prescription Database ensured accurate information on the use of thyroid medications in HUNT 3. The use of medications in HUNT 2 was assessed by self-report, which may be less accurate, but it seems unlikely that this difference between the surveys may explain the changes in prevalence. Participants with thyroid dysfunction in HUNT 2 were recommended to contact their general practitioner for follow-up, and their subsequent treatment could have influenced the prevalence of hypothyroidism in HUNT 3. However, this is not likely to explain the changes in prevalence in our study, because the prevalence of treated and untreated hypothyroidism in HUNT 3 did not differ substantially between participants who had their thyroid function tested in HUNT 2 and those who had not. A similar prevalence of levothyroxine use among the participants of HUNT 3 as in the total population of Nord-Trøndelag also weakens the possibility that selection bias may have influenced the results. For TPO antibodies, no comparison was made between the measurement methods used in HUNT 2 and HUNT 3, and changes in the prevalence of subclinical hypothyroidism by TPO antibody status should, therefore, be interpreted with caution.

Few other studies have examined changes in the prevalence of untreated hypothyroidism, but similar to our study, a study among elderly patients in Birmingham, England, suggested that the prevalence of untreated subclinical hypothyroidism decreased from $6 \%$ in 1988-1989 to 3\% around 2004 (11). More data are available on changes in thyroid hormone prescription. Thus, the annual number of thyroid hormone prescription items dispensed in England more than doubled from 1998 to 2007 (12), and in the Tayside region in Scotland, the prevalence of treated hypothyroidism increased by 63\% from 1994 to 2001 (13). In Denmark, the incidence rate of treated hypothyroidism increased by $\sim 80 \%$ from 1997 to 2008, which may be explained both by more extensive detection and treatment of hypothyroidism and by an increased incidence of hypothyroidism due to the introduction of iodized salt (14). However, the Norwegian population has long been considered to be iodine sufficient (15), and it seems unlikely that changes in iodine intake may explain the changes that we observed. Smoking (16, 17), alcohol consumption (18), and adiposity $(19,20,21)$ are other factors that could influence the prevalence of hypothyroidism or prevalence of high TSH concentrations, but statistical adjustment for differences in smoking habits, alcohol consumption, and BMI between the surveys did not substantially influence the changes in prevalence in our study.

The decline in the prevalence of untreated hypothyroidism in our study population was counterbalanced by an increased prevalence of treated hypothyroidism. This suggests that more extensive detection of hypothyroidism and more liberal treatment of subclinical hypothyroidism may explain the reduced prevalence of untreated hypothyroidism. In support of this suggestion, we also 
Table 4 Subtypes of untreated subclinical hypothyroidism defined by TSH concentration or TPO antibody status ${ }^{\text {a }}$ : prevalence in HUNT 2 and HUNT 3 and ratios of the prevalence in HUNT 3 to that in HUNT 2, adjusted for age.

\begin{tabular}{|c|c|c|c|c|c|c|}
\hline & \multicolumn{2}{|c|}{ HUNT $2^{\text {b }}(1995-1997)$} & \multicolumn{2}{|c|}{ HUNT $3^{\mathrm{c}}(2006-2008)$} & \multirow[b]{2}{*}{ Prevalence ratio } & \multirow[b]{2}{*}{$95 \% \mathrm{Cl}$} \\
\hline & Prevalence (\%) & $95 \% \mathrm{Cl}$ & Prevalence (\%) & $95 \% \mathrm{Cl}$ & & \\
\hline \multicolumn{7}{|l|}{ Women } \\
\hline TSH 4.6-6.9 mU/l & 1.95 & $1.68-2.23$ & 0.89 & $0.78-1.00$ & 0.46 & $0.38-0.54$ \\
\hline TSH 7.0-9.9 mU/l & 0.68 & $0.46-0.90$ & 0.12 & $0.08-0.16$ & 0.17 & $0.11-0.27$ \\
\hline $\mathrm{TSH} \geq 10.0 \mathrm{mU} / \mathrm{l}$ & 0.33 & $0.21-0.45$ & 0.06 & $0.03-0.09$ & 0.18 & $0.10-0.32$ \\
\hline TPO antibody negative & 1.20 & $0.96-1.44$ & 0.38 & $0.31-0.46$ & 0.32 & $0.25-0.41$ \\
\hline TPO antibody positive & 1.71 & $1.42-1.99$ & 0.68 & $0.58-0.78$ & 0.40 & $0.33-0.49$ \\
\hline \multicolumn{7}{|l|}{ Men } \\
\hline TSH 4.6-6.9 mU/l & 1.59 & $1.29-1.89$ & 0.76 & $0.65-0.87$ & 0.48 & $0.38-0.60$ \\
\hline TSH 7.0-9.9 mU/l & 0.37 & $0.22-0.52$ & 0.18 & $0.12-0.23$ & 0.49 & $0.30-0.79$ \\
\hline $\mathrm{TSH} \geq 10.0 \mathrm{mU} / \mathrm{l}$ & 0.19 & $0.11-0.26$ & 0.06 & $0.03-0.09$ & 0.30 & $0.15-0.57$ \\
\hline TPO antibody negative & 1.27 & $1.02-1.51$ & 0.53 & $0.43-0.62$ & 0.42 & $0.33-0.53$ \\
\hline TPO antibody positive & 0.83 & $0.58-1.07$ & 0.45 & $0.36-0.54$ & 0.55 & $0.39-0.76$ \\
\hline
\end{tabular}

${ }^{a}$ The proportion of subclinically hypothyroid participants with available TPO antibody status was $98 \%$ in HUNT 2 and $99 \%$ in HUNT 3 .

b23 274 women and 10643 men.

c26 822 women and 22358 men.

observed that a high proportion of subclinically hypothyroid individuals in HUNT 2 were subsequently treated with levothyroxine in HUNT 3. The latter observation should be interpreted with caution, however, because we do not know the participants' thyroid function at the initiation of levothyroxine treatment and information on thyroid function in HUNT 3 was available for only $49 \%$ of people with untreated subclinical hypothyroidism in HUNT 2.

Changes in the prevalence of hypothyroidism may differ between populations due to differences in the frequency of thyroid function testing, access to levothyroxine treatment, and clinical practice followed for the treatment of subclinical hypothyroidism. In Norway, there is easy access to primary health care, thyroid function testing is performed liberally, and most of the costs for thyroid function testing and levothyroxine treatment are reimbursed. There are no national guidelines on screening or treatment for hypothyroidism, and the choice to treat subclinical hypothyroidism or not is made by the individual physicians, most often general practitioners. The strong decline in the prevalence of untreated overt hypothyroidism and subclinical hypothyroidism with TSH concentrations above $10 \mathrm{mU} / \mathrm{l}$ suggests that such hypothyroidism is now most often treated, as recommended $(1,22)$. For subclinical hypothyroidism with a mild TSH concentration elevation, there is no consensus on the benefit of treatment $(1,22,23,24)$, and mild TSH concentration elevation may frequently be due to causes other than

Table 5 Prevalence of types of hypothyroidism in HUNT 3 (2006-2008) among people with untreated subclinical hypothyroidism in HUNT 2 (1995-1997) who had also participated in HUNT $3,{ }^{a}$ by type of subclinical hypothyroidism ${ }^{\mathrm{b}}$ in HUNT 2 , in women and men.

\begin{tabular}{|c|c|c|c|c|c|c|c|c|c|c|c|c|c|c|}
\hline \multirow{3}{*}{$\begin{array}{l}\text { Type of } \\
\text { hypothyroidism } \\
\text { in HUNT } 3\end{array}$} & \multicolumn{14}{|c|}{ Type of untreated subclinical hypothyroidism in HUNT 2} \\
\hline & \multicolumn{2}{|c|}{ Any } & \multicolumn{2}{|c|}{$\begin{array}{l}\text { TSH 4.6- } \\
6.9 \mathrm{mU} / \mathrm{l} \\
\text { TPOAb- }\end{array}$} & \multicolumn{2}{|c|}{$\begin{array}{l}\text { TSH 4.6- } \\
6.9 \mathrm{mU} / \mathrm{l} \\
\text { TPOAb+ }\end{array}$} & \multicolumn{2}{|c|}{$\begin{array}{l}\text { TSH 7.0- } \\
9.9 \mathrm{mU} / \mathrm{l} \\
\text { TPOAb- }\end{array}$} & \multicolumn{2}{|c|}{$\begin{array}{l}\text { TSH 7.0- } \\
9.9 \mathrm{mU} / \mathrm{l} \\
\text { TPOAb+ }\end{array}$} & \multicolumn{2}{|c|}{$\begin{array}{c}\text { TSH } \\
\geq 10.0 \mathrm{mU} / \mathrm{l}, \\
\text { TPOAb- }\end{array}$} & \multicolumn{2}{|c|}{$\begin{array}{c}\text { TSH } \\
\geq 10.0 \mathrm{mU} / \mathrm{l}, \\
\text { TPOAb }+\end{array}$} \\
\hline & $n$ & $\%$ & $n$ & $\%$ & $n$ & $\%$ & $n$ & $\%$ & $n$ & $\%$ & $n$ & $\%$ & $n$ & $\%$ \\
\hline Women & \multicolumn{2}{|c|}{$(n=403)$} & \multicolumn{2}{|c|}{$(n=114)$} & \multicolumn{2}{|c|}{$(n=157)$} & \multicolumn{2}{|c|}{$(n=25)$} & \multicolumn{2}{|c|}{$(n=59)$} & \multicolumn{2}{|c|}{$(n=7)$} & \multicolumn{2}{|c|}{$(n=36)$} \\
\hline Treated & 265 & 66 & 40 & 35 & 113 & 72 & 16 & 64 & 55 & 93 & 3 & 43 & 35 & 97 \\
\hline Untreated overt & 2 & 0.5 & 0 & 0 & 2 & 1 & 0 & 0 & 0 & 0 & 0 & 0 & 0 & 0 \\
\hline Untreated subclinical & 38 & 9 & 13 & 11 & 19 & 12 & 1 & 4 & 2 & 3 & 2 & 29 & 0 & 0 \\
\hline No hypothyroidism & 98 & 24 & 61 & 54 & 23 & 15 & 8 & 32 & 2 & 3 & 2 & 29 & 1 & 3 \\
\hline Men & \multicolumn{2}{|c|}{$(n=114)$} & \multicolumn{2}{|c|}{$(n=51)$} & \multicolumn{2}{|c|}{$(n=23)$} & \multicolumn{2}{|c|}{$(n=7)$} & \multicolumn{2}{|c|}{$(n=11)$} & \multicolumn{2}{|c|}{$(n=2)$} & \multicolumn{2}{|c|}{$(n=19)$} \\
\hline Treated & 50 & 44 & 10 & 20 & 11 & 48 & 3 & 43 & 7 & 64 & 2 & 100 & 16 & 84 \\
\hline Untreated overt & 3 & 3 & 0 & 0 & 1 & 4 & 0 & 0 & 1 & 9 & 0 & 0 & 1 & 5 \\
\hline Untreated subclinical & 20 & 18 & 12 & 24 & 4 & 17 & 1 & 14 & 2 & 18 & 0 & 0 & 1 & 5 \\
\hline No hypothyroidism & 41 & 36 & 29 & 57 & 7 & 30 & 3 & 43 & 1 & 9 & 0 & 0 & 1 & 5 \\
\hline
\end{tabular}

${ }^{a}$ Of 801 women and 260 men with untreated subclinical hypothyroidism in HUNT 2, 403 (50\%) of women and 114 (44\%) of men participated in HUNT 3. ${ }^{b}$ Defined by TSH concentration and by negative (TPOAb - ) or positive (TPOAb +) TPO antibody status, using a TPO antibody concentration of $200 \mathrm{U} / \mathrm{ml}$ as the cut-off. TPO antibody concentrations were measured in $398(99 \%)$ of women and $113(99 \%)$ of men with untreated subclinical hypothyroidism in HUNT 2 who had also participated in HUNT 3. 
Table 6 Prevalence of hypothyroidism among participants aged $\geq 50$ years of HUNT 3 who did or did not have their TSH concentrations measured in HUNT 2, adjusted for age.

\begin{tabular}{|c|c|c|c|c|c|c|}
\hline \multirow{2}{*}{$\begin{array}{l}\text { Type of } \\
\text { hypothyroidism }\end{array}$} & \multicolumn{2}{|c|}{$\begin{array}{l}\text { TSH concentrations not measured in } \\
\text { HUNT } 2^{\mathrm{a}}\end{array}$} & \multicolumn{2}{|c|}{$\begin{array}{l}\text { TSH concentrations measured in } \\
\text { HUNT } 2^{\mathrm{b}}\end{array}$} & \multirow[b]{2}{*}{ Prevalence ratio $^{c}$} & \multirow[b]{2}{*}{$95 \% \mathrm{Cl}$} \\
\hline & Prevalence (\%) & $95 \% \mathrm{Cl}$ & Prevalence (\%) & $95 \% \mathrm{Cl}$ & & \\
\hline \multicolumn{7}{|l|}{ Women } \\
\hline Untreated $^{d}$ & 1.7 & $1.1-2.3$ & 1.4 & $1.2-1.6$ & 0.80 & $0.55-1.17$ \\
\hline Treated & 10.7 & $9.3-12.1$ & 12.1 & $11.5-12.6$ & 1.13 & $0.98-1.29$ \\
\hline Any & 12.4 & $11.0-13.9$ & 13.4 & $12.9-14.0$ & 1.08 & $0.95-1.23$ \\
\hline \multicolumn{7}{|l|}{ Men } \\
\hline Untreated $^{d}$ & 1.5 & $1.3-1.8$ & 1.3 & $1.0-1.5$ & 0.82 & $0.61-1.10$ \\
\hline Treated & 2.8 & $2.5-3.2$ & 3.4 & $2.9-3.8$ & 1.19 & $0.98-1.44$ \\
\hline Any & 4.4 & $3.9-4.8$ & 4.6 & $4.1-5.2$ & 1.06 & $0.91-1.24$ \\
\hline
\end{tabular}

a2382 women and 7910 men.

b12 805 women and 5504 men.

${ }^{\mathrm{c}}$ Prevalence ratio of participants who had their TSH concentrations measured in HUNT 2 to those who had not. ${ }^{\mathrm{d} O v e r t}$ or subclinical.

hypothyroidism, including obesity $(19,20)$, age-related physiological changes in pituitary-thyroid axis function $(25,26)$, or simply being in the upper tail of the physiological distribution of TSH concentrations. In a study carried out in the Mayo Clinic in 1995-1996,
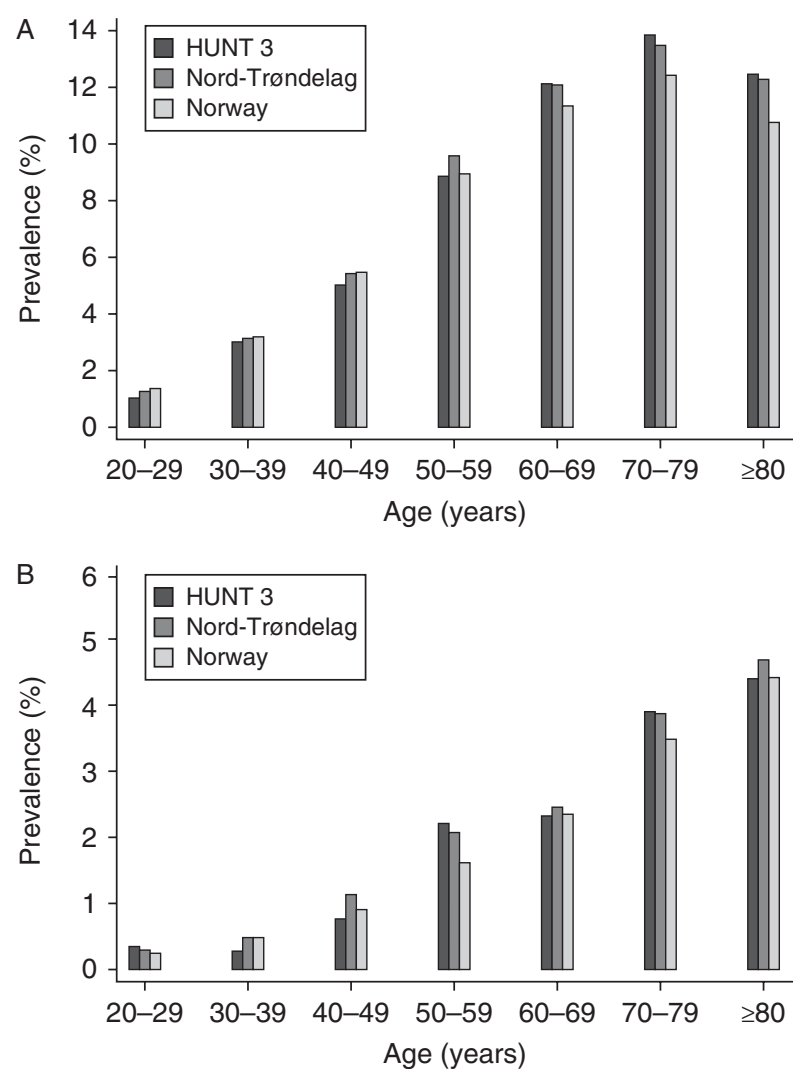

Figure 2 Prevalence (\%) of levothyroxine use in 2005 among the participants of HUNT 3, the total population of Nord-Trøndelag, and the total population of Norway, by age group, in women $(A)$ and men (B). levothyroxine was prescribed for only $20 \%$ of people with serum TSH concentrations of 5-10 mU/l without evidence of autoimmune thyroiditis (27). The declining prevalence of mild TSH concentration elevation without TPO antibodies that we observed may suggest that people with a mild TSH concentration elevation without evidence of autoimmune thyroiditis are increasingly being treated with levothyroxine.

In conclusion, the prevalence of untreated overt and subclinical hypothyroidism in the Nord-Trøndelag county in Norway was more than halved from 19951997 to 2006-2008, and the decline was counterbalanced by an increased prevalence of treated hypothyroidism. Increased thyroid function testing and more liberal treatment of subclinical hypothyroidism may explain these changes. The findings suggest that prevalence of untreated hypothyroidism in populations with easy access to thyroid function testing and levothyroxine treatment may now be low.

\section{Declaration of interest}

The authors declare that there is no conflict of interest that could be perceived as prejudicing the impartiality of the research reported.

\section{Funding}

This work was supported by the Research Council of Norway, the Norwegian University of Science and Technology, and Trondheim University Hospital. Financial support was also obtained from Wallac Oy (Turku, Finland) for TSH measurements in HUNT 2.

\section{Acknowledgements}

The HUNT Study is a collaborative effort of the HUNT Research Centre (Faculty of Medicine, Norwegian University of Science and Technology), Nord-Trøndelag County Council, Central Norway Health Authority, and the Norwegian Institute of Public Health. The HUNT Research Center and the Norwegian Prescription Database provided the data. The authors thank Anders Svare (Nord-Trøndelag Hospital Trust) for comparing the methods of TSH measurement used in HUNT 2 and HUNT 3. 


\section{References}

1 Biondi B \& Cooper DS. The clinical significance of subclinical thyroid dysfunction. Endocrine Reviews $2008 \quad 29$ 76-131. (doi:10.1210/er.2006-0043)

2 Bjoro T, Holmen J, Kruger O, Midthjell K, Hunstad K, Schreiner T, Sandnes L \& Brochmann H. Prevalence of thyroid disease, thyroid dysfunction and thyroid peroxidase antibodies in a large, unselected population. The Health Study of Nord-Trondelag (HUNT). European Journal of Endocrinology 2000143 639-647. (doi:10.1530/eje.0.1430639)

3 Canaris GJ, Manowitz NR, Mayor G \& Ridgway EC. The Colorado thyroid disease prevalence study. Archives of Internal Medicine 2000 160 526-534. (doi:10.1001/archinte.160.4.526)

4 Hollowell JG, Staehling NW, Flanders WD, Hannon WH, Gunter EW, Spencer CA \& Braverman LE. Serum TSH, T(4), and thyroid antibodies in the United States population (1988 to 1994): National Health and Nutrition Examination Survey (NHANES III). Journal of Clinical Endocrinology and Metabolism 200287 489-499. (doi:10.1210/jc.87.2.489)

5 Tunbridge WM, Evered DC, Hall R, Appleton D, Brewis M, Clark F, Evans JG, Young E, Bird T \& Smith PA. The spectrum of thyroid disease in a community: the Whickham survey. Clinical Endocrinology 19777 481-493. (doi:10.1111/j.1365-2265.1977. tb01340.x)

6 Vanderpump MP. The epidemiology of thyroid disease. British Medical Bulletin 201199 39-51. (doi:10.1093/bmb/ldr030)

7 Rodondi N, den Elzen WP, Bauer DC, Cappola AR, Razvi S, Walsh JP, Asvold BO, Iervasi G, Imaizumi M, Collet TH et al. Subclinical hypothyroidism and the risk of coronary heart disease and mortality. Journal of the American Medical Association 2010 304 1365-1374. (doi:10.1001/jama.2010.1361)

8 Holmen J, Midthjell K, Krüger Ø, Langhammer A, Holmen TL, Bratberg GH, Vatten LJ \& Lund-Larsen PG. The Nord-Trøndelag Health Study 1995-97 (HUNT 2): objectives, contents, methods, and participation. Norsk Epidemiologi 200313 19-32.

9 Krokstad S, Langhammer A, Hveem K, Holmen T, Midthjell K, Stene T, Bratberg G, Heggland J \& Holmen J. Cohort profile: the HUNT Study, Norway. International Journal of Epidemiology 2013 42 968-977. (doi:10.1093/ije/dys095)

10 Collet TH, Gussekloo J, Bauer DC, den Elzen WP, Cappola AR, Balmer P, Iervasi G, Asvold BO, Sgarbi JA, Volzke H et al. Subclinical hyperthyroidism and the risk of coronary heart disease and mortality. Archives of Internal Medicine 2012172 799-809. (doi:10.1001/archinternmed.2012.402)

11 Wilson S, Parle JV, Roberts LM, Roalfe AK, Hobbs FD, Clark P, Sheppard MC, Gammage MD, Pattison HM \& Franklyn JA. Prevalence of subclinical thyroid dysfunction and its relation to socioeconomic deprivation in the elderly: a community-based cross-sectional survey. Journal of Clinical Endocrinology and Metabolism 200691 4809-4816. (doi:10.1210/jc.2006-1557)

12 Mitchell AL, Hickey B, Hickey JL \& Pearce SH. Trends in thyroid hormone prescribing and consumption in the UK. BMC Public Health 20099 132. (doi:10.1186/1471-2458-9-132)

13 Leese GP, Flynn RV, Jung RT, Macdonald TM, Murphy MJ \& Morris AD. Increasing prevalence and incidence of thyroid disease in Tayside, Scotland: the Thyroid Epidemiology Audit and Research Study (TEARS). Clinical Endocrinology $2008 \quad 68$ 311-316. (doi:10.1111/j.1365-2265.2007.03051.x)

14 Cerqueira C, Knudsen N, Ovesen L, Laurberg P, Perrild H, Rasmussen LB \& Jorgensen T. Doubling in the use of thyroid hormone replacement therapy in Denmark: association to iodization of salt? European Journal of Epidemiology $2011 \mathbf{2 6}$ 629-635. (doi:10.1007/s10654-011-9590-5)
15 Kapelrud H, Frey H \& Theodorsen L. Excretion of iodine in the urine. A study from 6 different Norwegian districts in 1985. Tidsskrift for Den Norske Laegeforening 1987107 1320-1321, 1317.

16 Asvold BO, Bjoro T, Nilsen TI \& Vatten LJ. Tobacco smoking and thyroid function: a population-based study. Archives of Internal Medicine 2007167 1428-1432. (doi:10.1001/archinte.167.13.1428)

17 Carle A, Bulow Pedersen I, Knudsen N, Perrild H, Ovesen L, Banke Rasmussen L, Jorgensen T \& Laurberg P. Smoking cessation is followed by a sharp but transient rise in the incidence of overt autoimmune hypothyroidism - a population-based, case-control study. Clinical Endocrinology 201277 764-772. (doi:10.1111/j. 1365-2265.2012.04455.x)

18 Carle A, Pedersen IB, Knudsen N, Perrild H, Ovesen L, Rasmussen LB, Jorgensen T \& Laurberg P. Moderate alcohol consumption may protect against overt autoimmune hypothyroidism: a population-based case-control study. European Journal of Endocrinology 2012167 483-490. (doi:10.1530/EJE-12-0356)

19 Reinehr T. Obesity and thyroid function. Molecular and Cellular Endocrinology 2010316 165-171. (doi:10.1016/j.mce.2009. $06.005)$

20 Rotondi M, Leporati P, La Manna A, Pirali B, Mondello T, Fonte R, Magri F \& Chiovato L. Raised serum TSH levels in patients with morbid obesity: is it enough to diagnose subclinical hypothyroidism? European Journal of Endocrinology 2009160 403-408. (doi:10.1530/EJE-08-0734)

21 Svare A, Nilsen TI, Bjoro T, Asvold BO \& Langhammer A. Serum TSH related to measures of body mass: longitudinal data from the HUNT Study, Norway. Clinical Endocrinology 2011 74 769-775. (doi:10.1111/j.1365-2265.2011.04009.x)

22 Surks MI, Ortiz E, Daniels GH, Sawin CT, Col NF, Cobin RH, Franklyn JA, Hershman JM, Burman KD, Denke MA et al. Subclinical thyroid disease: scientific review and guidelines for diagnosis and management. Journal of the American Medical Association 2004291 228-238. (doi:10.1001/jama.291.2.228)

23 Gharib H, Tuttle RM, Baskin HJ, Fish LH, Singer PA \& McDermott MT. Subclinical thyroid dysfunction: a joint statement on management from the American Association of Clinical Endocrinologists, the American Thyroid Association, and the Endocrine Society. Journal of Clinical Endocrinology and Metabolism 200590 581-585 discussion 586-587. (doi:10.1210/jc.2004-1231)

24 Helfand M. Screening for subclinical thyroid dysfunction in nonpregnant adults: a summary of the evidence for the U.S. Preventive Services Task Force. Annals of Internal Medicine 2004 140 128-141. (doi:10.7326/0003-4819-140-2-20040120000015)

25 Bremner AP, Feddema P, Leedman PJ, Brown SJ, Beilby JP, Lim EM, Wilson SG, O'Leary PC \& Walsh JP. Age-related changes in thyroid function: a longitudinal study of a community-based cohort. Journal of Clinical Endocrinology and Metabolism 201297 1554-1562. (doi:10.1210/jc.2011-3020)

26 Surks MI \& Hollowell JG. Age-specific distribution of serum thyrotropin and antithyroid antibodies in the US population: implications for the prevalence of subclinical hypothyroidism. Journal of Clinical Endocrinology and Metabolism $2007 \mathbf{9 2}$ 4575-4582. (doi:10.1210/jc.2007-1499)

27 Fatourechi V, Lankarani M, Schryver PG, Vanness DJ, Long KH \& Klee GG. Factors influencing clinical decisions to initiate thyroxine therapy for patients with mildly increased serum thyrotropin (5.1-10.0 mIU/l). Mayo Clinic Proceedings. Mayo Clinic $2003 \mathbf{7 8}$ 554-560. (doi:10.4065/78.5.554)

Received 31 May 2013

Revised version received 7 August 2013

Accepted 23 August 2013 